\title{
Congenital Toxoplasmosis with Severe Haemolytic Anaemia: An Unusual Presentation
}

\author{
ADITI RAWAT ${ }^{1}$, PARESH THAKKAR ${ }^{2}$, BAKUL B. JAVADEKAR ${ }^{3}$
}

\section{Introduction}

Congenital toxoplasmosis has a wide spectrum of clinical manifestations, but it is subclinical in approximately $80 \%$ of infected newborns. ${ }^{1}$ Although multiple risk factors are present, maternal infection is primarily attributed to the consumption of meat or other edibles contaminated with oocyst of toxoplasma. There is an increasing risk of transplacental transmission and decreasing severity of infection with increasing gestational age..$^{2,3}$ The classic triad ${ }^{2}$ of congenital toxoplasmosis is chorioretinitis, intracranial calcifications, and hydrocephalus. In our case none of the classical symptoms were seen and this type of presentation with severe haemolytic anaemia and hepatosplenomegaly is rare and only a few cases like these have been reported.

\section{Case study}

A full term small for date baby, birth weight $1.58 \mathrm{~kg}$ was delivered to a 25 year old by normal vaginal delivery. No antenatal history of fever, lymphadenopathy, exanthematous illness, drug intake or exposure to cats was recalled by mother. Regular antenatal visits done and iron, folic acid, calcium supplements were given antenatally. Child was brought to neonatal ICU at first hour of life with tachypnoea, respiratory distress and grunting. Intravenous antibiotics were started for early onset septicaemia. Within 24 hours of life child developed jaundice and pallor with significant hepatosplenomegaly (Fig.-1). Progressive fall in haemoglobin was noticed in subsequent days with rising serum bilirubin and a strikingly high reticulocyte count (Table-I).

Klebsiella isolates were seen on blood culture. Transfusion of red cell concentrate given for anaemia. A petechial rash was observed on $7^{\text {th }}$ day with corresponding thrombocytopenia for which platelet transfusion was given. Further investigations to find out the cause of haemolysis were carried out which showed no deficiency of G6PD enzyme; normal osmotic fragility curve, normocytic normochromic RBC with occasional schistocytes on peripheral smear; negative direct coomb's test to rule out autoimmune haemolytic anaemia. Ultrasound abdomen was done which showed altered liver echo-texture suggestive of liver parenchymal disease but liver enzymes were in normal range. With a suspicion of TORCH infection,

Table-I

Serial laboratory investigations

\begin{tabular}{|c|c|c|c|c|c|c|}
\hline & $1^{\text {st }}$ Day & $3^{\text {rd }}$ Day & $5^{\text {th }}$ day & $7^{\text {th }}$ day & $9^{\text {th }}$ day & $12^{\text {th }}$ day \\
\hline Hemoglobin (gram\%) & 9.9 & 11.4 & 10.6 & 8.6 & 8.0 & 7.7 \\
\hline 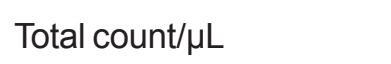 & $21 \times 10^{3}$ & $16.6 \times 10^{3}$ & $8.7 \times 10^{3}$ & $11.6 \times 10^{3}$ & $15.1 \times 10^{3}$ & $14 \times 10^{3}$ \\
\hline Platelet count $/ \mu \mathrm{L}$ & $45 \times 10^{3}$ & $56 \times 10^{3}$ & $32 \times 10^{3}$ & $16 \times 10^{3}$ & $63 \times 10^{3}$ & $15 \times 10^{3}$ \\
\hline Bilirubin (mg/dl) Total & 11.2 & 13.4 & & 16.3 & 12.0 & \\
\hline Direct & 3.0 & 4.0 & & 5.6 & 4.0 & \\
\hline Indirect & 8.2 & 9.4 & & 10.7 & 8.0 & \\
\hline Reticulo-cyte count (\%) & & 18 & & 12 & 8 & 5 \\
\hline
\end{tabular}

1. MD Resident (2nd year), Department of Pediatrics, S.S.G Hospital and Medical College, Vadodara.

2. Associate Professor, Department of Pediatrics, S.S.G Hospital and Medical College, Sayajigunj, Vadodara, Gujarat.

3. Professor and Head, Department of Pediatrics, S.S.G Hospital and Medical College, Sayajigunj, Vadodara, Gujarat.

Correspondence: Dr. Aditi Rawat, MD Resident (2nd year), Department of Pediatrics, S.S.G Hospital and Medical College, Vadodara, Child care Hospital, E-103,104 Baktawar Ram nagar, Indore, Madhya Pradesh. Email: aditirawat0691@gmail.com 
immunological assay was done which revealed high levels of IgM against toxoplasma pointing to diagnosis of congenital toxoplasmosis. IgM against cytomegalovirus was non reactive. Maternal TORCH titre revealed raised toxoplasma IgG and IgM. MRI Brain showed no evidence of calcifications and fundus examination showed no signs of chorioretinitis. Thereafter child was started on pyrimethamine and sulfadiazine and decreased haemolysis and clinical improvement was noted.

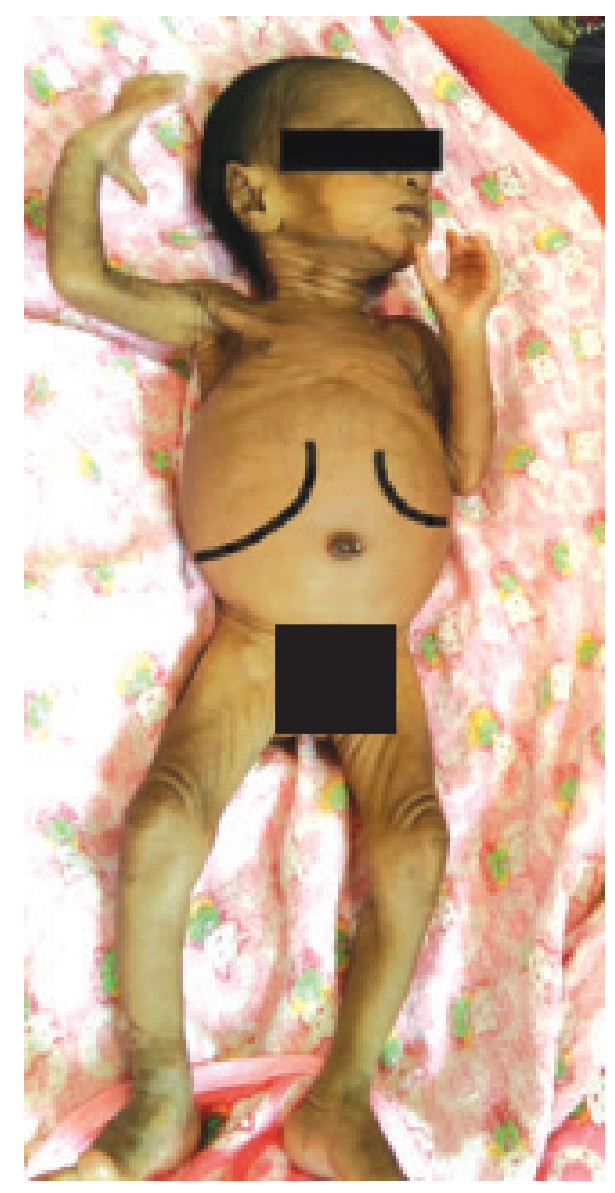

Fig.-1: Massive hepatosplenomegaly

\section{Discussion}

TORCH constellation comprises of Toxoplasma, Others (syphilis, Parvovirus B19, Varicella zoster, Hepatitis B virus), Rubella, Cytomegalovirus, Herpes viruses which are important causes of intrauterine infection. Congenital toxoplasmosis can have various effects ranging from asymptomatic infection to foetal loss. ${ }^{2,3}$

The infection is caused by Toxoplasma gondii, most common of all the protozoan infections. ${ }^{2}$ All cat family
(Felidae) animals are definitive hosts and all other animals including humans are accidentally infected. In congenital infection rate of transmission is directly proportional to gestational age. ${ }^{3}$ Conversely infections acquired during the third trimester are most often asymptomatic at birth. ${ }^{3}$ Unfortunately 70 to $90 \%$ of these infants who appear normal at birth develop significant clinical illness by young adulthood. ${ }^{4}$

CNS involvement is hallmark of congenital Toxoplasma infection. ${ }^{2}$ Fever, hydrocephalus or microcephaly, hepato-splenomegaly, convulsions, chorioretinitis and cerebral calcifications are the classic features of congenital toxoplasmosis. ${ }^{5,6}$ Other findings included rash, myocarditis, respiratory distress, hearing defects, thrombocytopenia, Iymphocytosis, and nephrotic syndrome. Some infected children without overt disease as neonates may escape serious consequences of the infection; however, a significant number develop chorioretinitis, strabismus, blindness, hydrocephalus or microcephaly, cerebral calcifications, developmental delay, epilepsy, or deafness months or years later. ${ }^{6,7}$ Presentation only in the form haemolytic anaemia and hepatosplenomegaly is uncommon.

Couvreur et $\mathrm{al}^{8}$ in a series of 300 cases of congenital toxoplasmosis found jaundice in $20 \%$ and hepatosplenomegaly in $18 \%$.

In the three cases described by Bain et al ${ }^{9}$; a stillborn baby, one who died immediately after birth and a stillborn macerated foetus of 30 weeks' gestation. In the first two cases toxoplasma were isolated and in the third the serological tests on the mother's serum were diagnostic of toxoplasmosis. Clinically all 3 infants had splenomegaly, two had hepatomegaly and in the first two the placenta was large and flabby, giving rise to a suspicion of haemolytic disease of the newborn.

One case reported by Leslie et $\mathrm{al}^{10}$ with congenital toxoplasmosis had a similar presentation with jaundice (direct hyperbilirubinemia) and heaptosplenomegaly on $2^{\text {nd }}$ day with an episode of haemolytic crisis on $27^{\text {th }}$ day of life.

Congenital toxoplasmosis is a severe disease that can be treated and prevented. Spiramycin (rovamycin) is the drug of choice which prevents the transplacental transmission of the parasite. ${ }^{2,3}$ However, if the parasite has already crossed the placenta, spiramycin cannot reverse the damage caused to the fetus. ${ }^{2}$ For treating the postnatal toxoplasmosis sulfadiazine and 
pyrimethamine combination is the best option. ${ }^{2,3}$ Prevention is better than cure and this disease can be effectively prevented by educating pregnant women and other women of childbearing age about not ingesting raw or undercooked meat and protecting themselves against exposure to cat litter or contaminated soil.

The prognosis for the untreated infant is poor; however, when antibiotic therapy is started early, the rate of sequelae is reduced significantly. ${ }^{3}$ Regular follow up for neurodevelopment assessment and ophthalmological examination is recommended.

\section{Conclusion}

Clinical spectrum of congenital toxoplasmosis is very wide and a high degree of suspicion is required for timely diagnosis. In case of congenital infections mother may be asymptomatic antenatally and thus thorough clinical examination of the neonate is the key point here. This unusual presentation of congenital toxoplasmosis in the form of hemoytic anemia serves as a learning point that a disease may not always present with its hall mark features.

Financial support: Self funded

\section{Conflict of interest: No conflicts}

\section{References}

1. Singh S, MunawwarA, Rao S, Mehta S, Hazarika NK. Serologic prevalence of Toxoplasma gondii in Indian women of child bearing age and effects of social and environmental factors. PLoS NegI Trop Dis. 2014;8:e2737.
2. Singh, Sarman.Congenital Toxoplasmosis: Clinical Features, Outcomes, Treatment, and Prevention. Tropical Parasitology. 2016;6:113-22.

3. Cloherty, John P, and Ann R. Stark. Manual of Neonatal Care. $7^{\text {th }}$ edition New York: LippincottRaven, 1998:656-63.

4. Boyer KM. Toxoplasmosis: Current status of diagnosis, treatment and prevention. Semin Pediatr Infect Dis. 2000;11:165-71.

5. Kieffer F, Wallon M. Congenital toxoplasmosis. Handb Clin Neurol. 2013;112:10991101.

6. McAuley, James B. Congenital Toxoplasmosis. Journal of the Pediatric Infectious Diseases Society. 2014;3: S30-S35.

7. De Vroede M, Dodion J, De Meuter F. Congenital toxoplasmosis: Late appearance of retinal lesions after treatment. Acta Paediatr Scand. 1979;68: 761-62.

8. Couvreur J, Desmonts G. Congenital and maternal toxoplasmosis. A review of 300 congenital cases. Dev Med Child Neurol. 1962;4:19-30.

9. Bain AD, Beattie CP, Beverley JK, Bowie JH, Flint WF. Congenital toxoplasmosis simulating haemolytic disease of the newborn. J Obstet Gynaecol Br Emp. 1956;63:826-32.

10. Nelson LG, Hodgman JE. Congenital Toxoplasmosis with Hemolytic Anemia. California Medicine. 1966;105:454-57. 